\title{
Pathogen-Induced Defense and Innate Immunity in Macroalgae
}

\author{
FLORIAN WEINBERGER* \\ Leibniz-Institut für Meereswissenschaften (IFM-GEOMAR), Düsternbrooker Weg 20, \\ 24105 Kiel, Germany
}

\begin{abstract}
Animals and vascular plants are known to defend themselves facultatively against pathogens, with innate receptors mediating their resistance. Macroalgal defense against microorganisms, in contrast, has until recently been regarded mainly as constitutive. Indeed, many macroalgae appear to be chemically defended at constantly high levels, and this is possibly one of the reasons why the first evidence of pathogen-aroused resistance in a macroalga was detected only a decade ago. Here, I summarize the results of studies that indicate the existence of pathogen-activated or pathogen-induced macroalgal defense. Most indications so far come from molecular investigations, which revealed major functional similarities among the defense systems of distant macroalgal clades and the innate immune systems of vascular plants and metazoans. Homologies exist in the primary and secondary defense-activating signals, as well as in the enzymes that are involved and the cellular responses that are activated. This strongly suggests that innate immunity also exists in relatively distinct macroalgal clades. However, a macroalgal receptor still needs to be isolated and characterized, and the molecular concept of macroalgal receptor-mediated immunity needs to be complemented with an ecological perspective on pathogen-induced defense, to develop a joint neuroecological perspective on seaweed-microbe interactions.
\end{abstract}

Received 29 March 2007; accepted 5 July 2007.

* E-mail: fweinberger@ifm-geomar.de

Abbreviations: $\mathrm{CHBr}_{3}$, bromoform; $\mathrm{H}_{2} \mathrm{O}_{2}$, hydrogen peroxide; $\mathrm{HR}$, hypersensitive response; LPS, lipopolysaccharide; MAMP, microbe-associated molecular pattern; $\mathrm{NO} \bullet$, nitric oxide; $\mathrm{O}_{2}{ }^{-} \bullet$, superoxide; PIMP, pathogen-induced molecular pattern; ROS, reactive oxygen species.

\section{The (Missing?) Ecological Perspective: Pathogen- Induced Defense}

As has been pointed out by Steinberg and deNys (2002), the defense ecology of macroalgae has until recently been dominated by investigations of seaweed/herbivore interactions. The first example of induced macroalgal defense against herbivores was detected two decades ago, and an increasing body of literature confirms that macroalgae often respond to grazers with an induced antiherbivore defense (for reviews, see Amsler and Fairhead, 2006; Toth and Pavia, 2007). Studies of seaweed-microbe interactions have lagged behind, mainly for methodological reasons. The characterization of alga-associated microorganisms is still in an early stage, since suitable tools for the analysis of epiphytic bacterial communities-including non-cultivatable components-were not available until rDNA sequencing techniques were introduced into this field of research (Ashen and Goff, 2000; Meusnier et al., 2001). Seaweedassociated microorganisms typically live embedded in highly complex matrices; this, together with their relatively short life span, also complicates the design of ecological studies. Our understanding of the interactions between microorganisms and macroalgae and with each other is therefore rudimentary at best.

Microorganisms grow to higher densities in water than in air (Engel et al., 2002). The aquatic environment generally favors the development of microbes and the formation of biofilms on surfaces, and macroalgae are associated and interact with these organisms. At the same time, mechanical defenses that are comparable to those of vascular plants are largely absent in macroalgae (Weinberger et al., 1999). Although certain microorganisms have been shown to provide their host macroalgae with growth factors, nutrients, or 
protection from settlement by other micro- or macrofoulers (Armstrong et al., 2001; Dobretsov and Qian, 2002; Matsuo et al., 2005; Zheng et al., 2005), others have been identified as the causative agents of infectious diseases with characteristic symptoms such as rot, bleaching, lesions, or malformations (Correa, 1996). However, major outbreaks of diseases are relatively rarely reported, which may in part be due to the limitations of our perception, but which also indicates that macroalgae are in most situations capable of coping with pathogens.

The presence of potential pathogens on healthy macroalgae was demonstrated by Küpper et al. (2002). The authors reinfected axenic kelp (Macrocystis pyrifera) with microorganisms that originated from healthy kelp specimens and observed that the algae were rapidly decomposed when their defense was blocked with specific enzyme inhibitors. Control specimens that were either uninhibited or uninfected remained healthy, and the authors concluded that the decomposition was due to opportunistic pathogens that were unable to attack defended kelp.

Many of the microorganisms that are associated with apparently healthy macroalgae have the enzymatic capacity to disintegrate tissues of their host. For example, $0.4 \%-$ $3.6 \%$ of the cultivatable bacteria associated with healthy Gracilaria sp. (as Gracilaria conferta) were capable of degrading its agar cell wall matrix (Weinberger et al., 1994). Similar observations have been reported for other red macroalgae (Largo et al., 1995; Jaffray et al., 1997), as well as for kelps (Lin et al., 2004). Degraders of phycocolloids are usually rare in nonalgal environmental samples (for this reason agar is traditionally used for the gellification of microbiological media), which indicates that their concentration on macroalgae has coevolutionary reasons. Massive increases in absolute and relative numbers of phycocolloid degraders are usually observed on stressed algal tissues with a reduced capacity for autodefense (Weinberger et al., 1994; Lin et al., 2004), suggesting that the microorganisms involved are opportunistic pathogens.

Optimal defense theory predicts that inducible defenses may evolve when pressure by pathogens is transient. Compared to constitutive resistance, facultative defenses imply a lower risk of pathogen adaptation (Boyd, 2006), as well as lower direct and indirect costs of defense under enemy-free conditions-for example, because energy is saved or exposure to autotoxic defensive compounds is reduced (Agrawal and Karban, 1999). On the other hand, facultative defenses also imply an increased risk of damage during the initial stage of pathogen attack (Järemo et al., 1999). Given that relatively dense biofilms containing potential pathogens are more or less permanently present on macroalgal surfaces, ecological intuition would not necessarily expect mechanisms of inducible antimicrobial defense in algae.

\section{The Molecular Perspective: Innate Immunity}

Much of the evidence for induced antimicrobial defense in macroalgae comes from molecular and physiological studies. These demonstrate important similarities between the defense systems of macroalgae, vascular plants, and metazoans. Inducible defense requires that the defensive level can be upregulated fast enough to contain the attacker before irreversible damage is done. On the cellular level, such upregulation is usually based upon molecular recognition of pathogen infections by receptors.

Adaptive receptors exist only in jawed vertebrates, but all metazoans and vascular plants - and apparently macroalgae as well-express innate receptors. These perceive microbeassociated molecular patterns, or MAMPs (Nürnberger et al., 2004), which are synonymously called general or exogenous elicitors. Usually MAMPs are highly conserved and not pathogen-specific, but specific of major groups of microorganisms that include pathogenic species. For example, lipopolysaccharides (LPS) and lipoteichoic acids-components of the outer cell envelopes of gram-negative and gram-positive bacteria, respectively-are examples of MAMPs that are perceived by many eukaryotes (Meyer $e t$ al., 2001; Farnell et al., 2003; He et al., 2003; Remer et al., 2003; Nürnberger et al., 2004). In addition to MAMPs, vascular plants also perceive breakdown products of their own cell wall that are released by glucohydrolytic activities from attacking phytopathogenic microbes; these breakdown products are called pathogen-induced molecular patterns (PIMPs; Mackey and McFall, 2006), or endogenous elicitors. For example, pectin oligosaccharides are established as elicitors of defense responses in vascular plants (Mathieu $e t$ al., 1991; Spiro et al., 1998; Nürnberger et al., 2004).

The responses and signaling pathways that are activated in vertebrates and vascular plants after MAMP or PIMP perception are complex and typical. As I will show in the next sections, the same pathways and responses are also activated in certain macroalgae after application of MAMPs or PIMPs. Such evidence today exists mainly for the brown macroalgal order of the Laminariales (kelps) and for red macroalgae of the genera Gracilaria and Chondrus (Table 1). These findings strongly indicate that macroalgal innate receptors exist, although no such receptor has yet been isolated and characterized.

\section{Receptor-Mediated Immunity in Red Macroalgae}

Vascular plants and metazoans typically respond after recognition of PIMPs or MAMPs with an oxidative burst, a transient production of reactive oxygen species (ROS) such as superoxide ions $\left(\mathrm{O}_{2}^{-\bullet}\right)$, hydrogen peroxide $\left(\mathrm{H}_{2} \mathrm{O}_{2}\right)$, or hydroxyl radicals $(\mathrm{OH} \bullet)$ (Grant and Loake, 2000; Delledonne et al., 2001; Nürnberger et al., 2004; Torres and Dangl, 2005). An oxidative burst was also observed as a first physiological indication of PIMP perception when the 


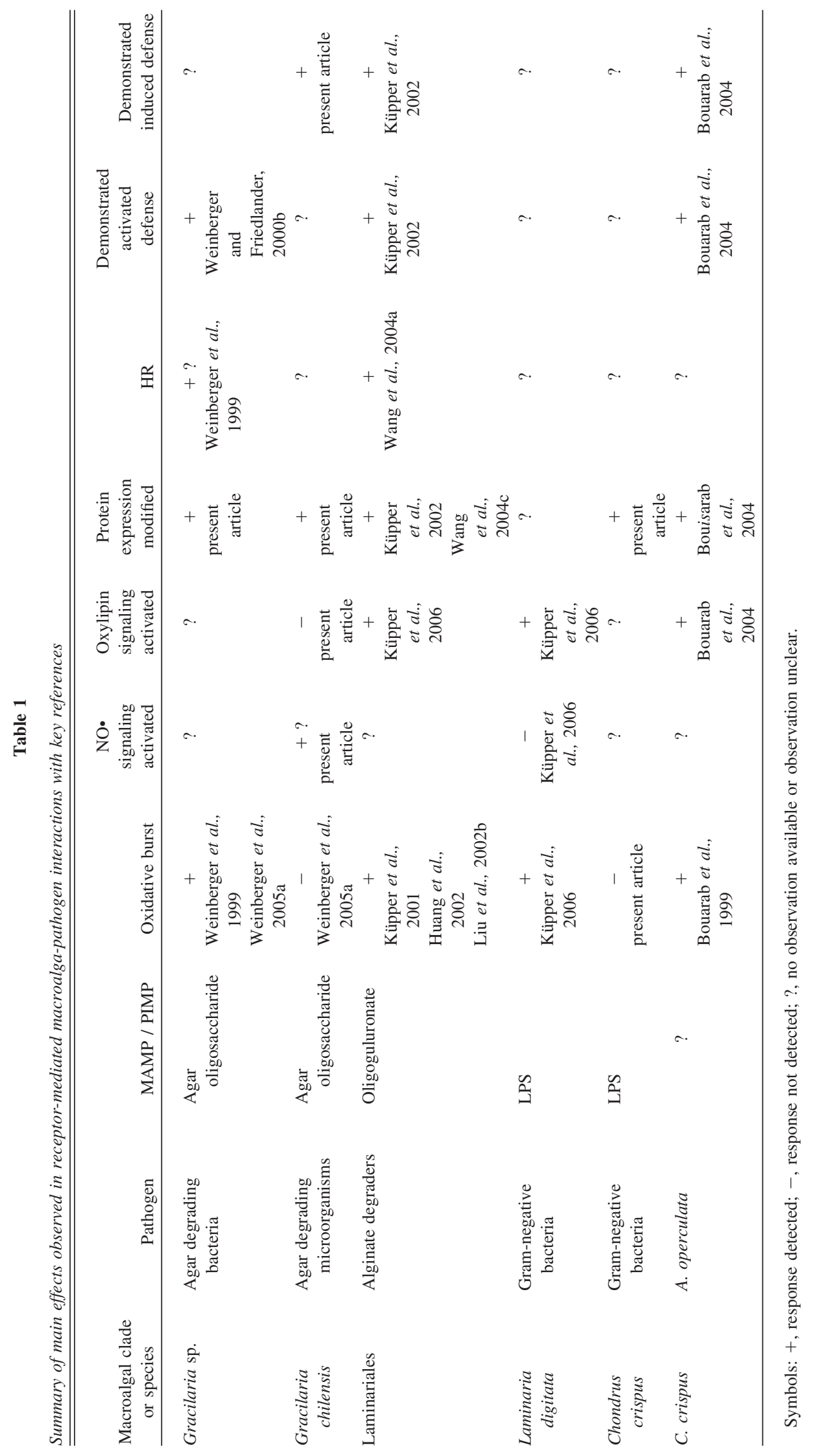


red macroalga Gracilaria sp. (as Gracilaria conferta) was exposed to products of the microbial degradation of its agar cell wall matrix (Weinberger et al., 1999). After exposure of Gracilaria sp. to agar oligosaccharides, $\mathrm{H}_{2} \mathrm{O}_{2}$ accumulated in the algal medium within minutes.

As could be shown by transmission electron microscopy, the site of ROS production was the plasma membrane of epidermal and subepidermal cells (Weinberger et al., 2005a). Further analysis of the oxidative burst response revealed that it was highly sensitive to diphenylene-iodonium, a specific inhibitor of NADPH-dependent enzymes, as well as to inhibitors of flavo-enzymes. The authors therefore concluded that NADPH oxidase (which is a flavoenzyme) located in the plasma membrane was probably the source of ROS after Gracilaria sp. was exposed to an elicitor (Weinberger et al., 2005a), as in vascular plants and metazoans (Torres and Dangl, 2005).

$\mathrm{NADPH}$-oxidases of vascular plants and animals are stimulated by $\mathrm{Ca}^{2+}$-ions (Keller et al., 1998; Sagi and Fluhr, 2001; Banfi et al., 2005), and $\mathrm{Ca}^{2+}$-ions are also required for the activation of NADPH oxidase in Gracilaria sp. after agar oligosaccharide exposure. This is indicated by the observation that $\mathrm{Ca}^{2+}$-channel inhibitors generally inhibit the response, while $\mathrm{Ca}^{2+}$-ionophores increase its intensity (Weinberger et al., 2005a).

The oxidative-burst response of Gracilaria sp. after agar oligosaccharide application was also prevented with protein kinase inhibitors and increased after application of phosphatase inhibitors, which indicated an involvement of phosphorylation events with NADPH oxidase activation (Weinberger et al., 2005a). After a response was elicited, Gracilaria sp. remained incapable of responding for $6 \mathrm{~h}$ (Weinberger et al., 2005a). Such a refractory state is typically observed after cellular recognition of chemical signals that activate phosphorylation events, because no unphosphorylated protein kinase substrate is available (Felix et al., 1993). In conclusion, the early signaling events between stimulation of agar oligosacharide receptors and activation of NADPH oxidase in Gracilaria sp. include protein phosphorylation and $\mathrm{Ca}^{2+}$-perception and appear similar in this way to those observed in vascular plants (Navazio et al., 2002) and vertebrates (Meier, 1996).

A further similarity between Gracilaria sp. and vascular plants is in the specificity of their receptors for PIMPs that are functionally analogous. Agar is a functional analog of pectin in the cell wall matrices of red algae. Both pectin and agar are linear polysaccharides, consisting of monosaccharide and disaccharide repeating units, respectively. Both microbial agarases and pectinases are endo-hydrolases and generate the repeating units as final products. The perception of agar oligosaccharides by Gracilaria sp. is affected by the oligosaccharide size (Weinberger et al., 2001). Saccharides consisting of six to eight disaccharide repeating units proved to be the most efficient in eliciting an oxidative burst and eliminating associated bacteria, while the disaccharide was not perceived. This is consistent with the observation that pectin oligosaccharides also appear to be best perceived when they are relatively long and consist of chains of 10 to 15 monosaccharides (Mathieu et al., 1991).

An indication that MAMPs may also be perceived by red macroalgae comes from a study of Chondrus crispus and its endophytic algal pathogen Acrochaete operculata (Bouarab et al., 1999). The authors reported that cell-free extract of $A$. operculata triggered an oxidative burst. The gametophytic generation of $C$. crispus, which is more resistant than the sporophytic generation to $A$. operculata, responded with a stronger release of ROS. The oxidative burst was sensitive to diphenylene iodonium and therefore probably catalyzed by an NADPH oxidase. Attempts to isolate the molecular signal were unsuccessful, because it was not consistently present in A. operculata extracts (F. Weinberger, unpubl. data). An origin from microorganisms that were associated with A. operculata rather than from A. operculata itself can therefore not be excluded.

Liposaccharide (LPS) and lipoteichoic acids isolated from the cell envelopes of gram-negative and gram-positive bacteria modified patterns of protein expression in $C$. crispus (Fig. 1), which strongly suggests that they are perceived by this alga. These compounds did not trigger an oxidative burst in $C$. crispus, which was also true in several confirmed cases of LPS perception in vascular plants (Erbs and Newman, 2003).

An oxidative burst per se is not necessarily a result of receptor activation, since sources other than NADPH oxidase may also generate ROS. In Gracilaria chilensis, a species closely related to Gracilaria sp., agar oligosaccharides did not activate NADPH oxidase, but were instead oxidized by an agar oligosaccharide oxidase located in the cell wall (Weinberger et al., 2005a). Similarly, A. operculata often contains-and excretes-important amounts of asparagine, which may serve as a substrate of cell-walllocated amino acid oxidase in C. crispus (Weinberger et al., 2002, 2005b). In both cases, important amounts of ROS may temporarily accumulate and even affect pathogens, but molecular perception is not required.

\section{Receptor-Mediated Immunity in Kelps}

Alginate is the functional analog of agar and pectin in kelps, and oligomeric degradation products of alginate rich in $\alpha$-1,4-L-guluronic acid have been shown to elicit an oxidative burst in kelp sporophytes (Küpper et al., 2001, 2002). Exposure of Laminaria digitata to $2.5 \mu \mathrm{g} \mathrm{l}^{-1}$ or more of oligoguluronate triggered a release of superoxide radicals. Cortical and young tissues generated more ROS than medullary and old tissues, respectively. No response was measured for $3 \mathrm{~h}$ after exposure, and pharmacological investigation with specific enzyme inhibitors indicated that 


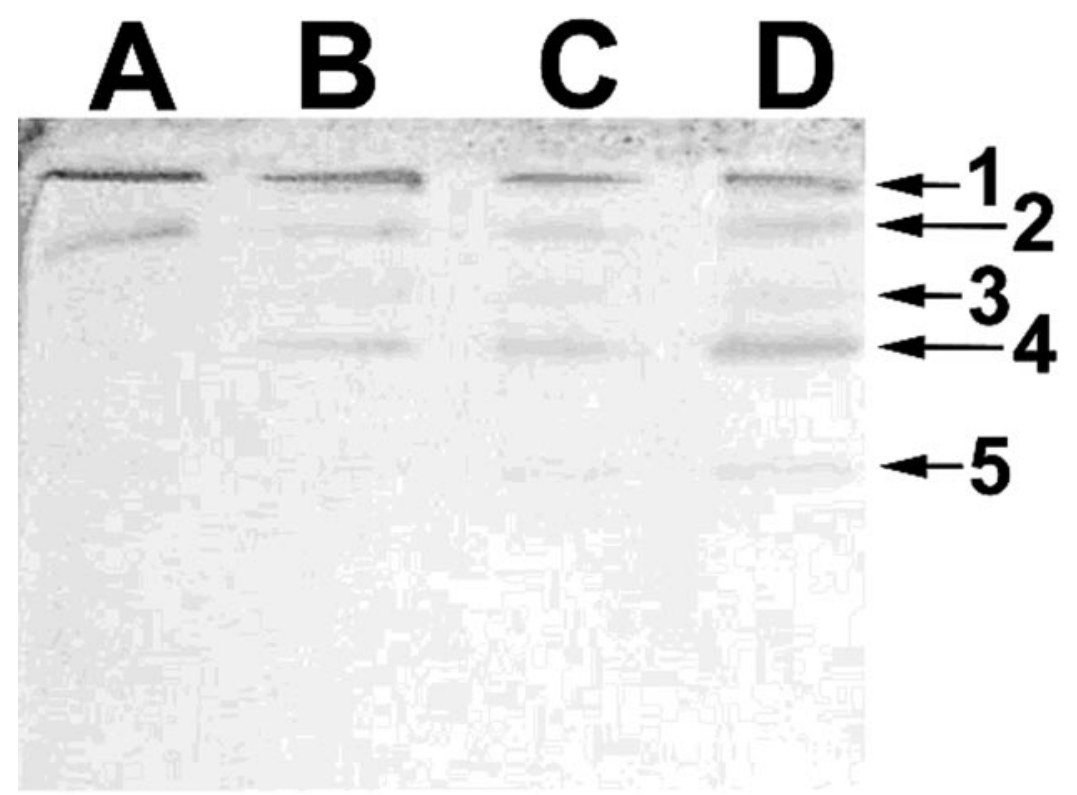

Figure 1. Expression of bromoperoxidases in Chondrus crispus as detected by gel electrophoresis under non-denaturating conditions. Lanes were loaded with $50 \mu \mathrm{g}$ of crude protein of $C$. crispus incubated for $24 \mathrm{~h}$ in seawater alone (A) or seawater with addition of $1 \mu \mathrm{g} \mathrm{ml}^{-1}$ of lipoteichoic acid of Staphylococcus aureus (B), lipopolysaccharide of Salmonella mortus-equi (C), or lipoteichoic acid of Bacillus subtilis (D). Band 2 represents the red algal pigment phycoerythrin; bands 1 and 3 to 5 represent different bromoperoxidases. Visibly, bands 3 to 5 were absent in untreated C. crispus. For development, the gel was soaked with $25 \mathrm{mmol}^{-1}$ TRIS buffer, $\mathrm{pH} 7.4$, in the presence of $10 \mu \mathrm{mol} \mathrm{l^{-1 }}$ potassium bromide, $90 \mu \mathrm{mol} \mathrm{l}^{-1} o$-dianisidine, and $0.45 \mathrm{mmol} \mathrm{l}^{-1} \mathrm{H}_{2} \mathrm{O}_{2}$.

the signal transduction chain after treatment with oligoguluronate signals in $L$. digitata probably includes protein kinases, as well as $\mathrm{Ca}^{2+}$ channels and anion channels.

The authors also reported that oligoguluronate application resulted in a transient uptake of potassium for about 5 min, which was correlated with medium alkalinization and followed by a massive efflux of potassium ions. Interestingly, application of ionophores of $\mathrm{K}^{+}, \mathrm{H}^{+}$, and $\mathrm{Ca}^{2+}$ also activated NADPH oxidase, and the authors therefore concluded that plasma membrane depolarization must be directly involved in the activation of NADPH oxidase in $L$. digitata. This is similar to the situation in vertebrates (Amatore et al., 2006), and different from that in vascular plants (Jabs et al., 1997) and red macroalgae (Weinberger et al., 2005b).

An NADPH-oxidase-mediated oxidative burst was also observed when $L$. digitata was challenged with LPS originating from the outer cell envelope of gram-negative bacteria (Küpper et al., 2006). Such responses to LPS have also been observed in some vascular plants (Meyer et al., 2001) and in metazoans (Farnell et al., 2003; He et al., 2003; Remer et al., 2003).

\section{Receptor-Mediated Protein Expression}

After perception of MAMPs or PIMPs, animals and vascular plants typically respond not only with instantaneous activation of constitutive enzymes such as NADPH oxidase, but also with upregulated expression of defense-related proteins. There is evidence that macroalgae respond in an analogous way to MAMPs and PIMPs. For example, an upregulation of phenylalanine-ammonia lyase, a key enzyme of the biosynthesis of aromatic compounds, was reported for Chondrus crispus gametophytes after incubation with cell-free extracts of the endophytic pathogen Acrochaete operculata. Within $24 \mathrm{~h}$, the enzyme was more strongly expressed, and this effect was correlated with increased resistance against A. operculata (Bouarab et al., 2004).

A similar response was reported for Laminaria digitata, in which autofluorescent compounds-interpreted by the authors as defense-related aromatic compounds-accumulated within $7 \mathrm{~d}$ after treatment with oligoguluronate (Küpper et al., 2002). This increase was positively correlated with resistance toward the endophyte Laminariocolax tomentosoides. In Laminaria japonica, the activity potential of polyphenol oxidase increased after infection with alginate-degrading microorganisms (Wang et al., 2004c), which also indicates modifications in the metabolism of phenolic compounds.

Treatment of $C$. crispus with lipoteichoic acids or LPS originating from the outer cell envelopes of various bacteria triggered expression of new isoforms of bromoperoxidase $24 \mathrm{~h}$ later (Fig. 1), suggesting that these MAMPs increase the algal capacity for synthesis of brominated defense com- 
pounds (see below). Exposure of different Gracilaria species to agar oligosaccharide resulted in an upregulation of agar oligosaccharide oxidoreductase $24 \mathrm{~h}$ later. The expression of this enzyme was positively correlated with resistance of Gracilaria chilensis toward attachment of the epiphytic filamentous alga Acrochaetium sp. (F. Weinberger, J. Beltrán, U. Lion, M.-L. Guillemin, unpubl. data).

\section{Secondary Signal Transduction}

Upregulation of specific proteins after MAMP or PIMP perception implies that intracellular signaling activates their transcription. ROS resulting from the oxidative burst, but also NO radicals, have been shown in animals and vascular plants to interact in a regulatory network that modifies protein expression (Jabs et al., 1997; Grant and Loake, 2000; Delledonne et al., 2001; Zeidler et al., 2004; Pitzschke et al., 2006). Using two different analytical methods, Küpper et al. (2006) failed to detected any NO• radicals in Laminaria digitata after exposure to LPS and concluded that they were probably not generated. In contrast, the upregulation of agar oligosaccharide oxidoreductase after treatment of Gracilaria chilensis with agar oligosaccharides could be prevented with various specific inhibitors of NO• synthase, suggesting that $\mathrm{NO} \cdot$ radicals were possibly involved in the regulation (F. Weinberger, unpubl. data).

Signaling cascades involving oxidized polyunsaturated fatty acids-so-called oxylipins - are activated after perception of external molecular signals in vascular plants as well as in animals (Lee et al., 2005), and this is also the case in macroalgae. Hydroperoxides derived from C20 polyunsaturated fatty acids (eicosanoids) regulate immune responses in metazoans (Soberman and Christmas, 2003; Stanley, 2006), whereas vascular plants use derivatives of C18 (octadecanoids) and C16 (hexadecanoids) fatty acids (Blee, 2002; Farmer et al., 2003). In both phyla, lipoxygenases catalyze the oxygenation of polyunsaturated fatty acids into hydroperoxy derivatives and other secondary products (Feusner and Wasternack, 2002; Soberman and Christmas, 2003). Both red and brown macroalgae also produce oxylipins, which are derived from $\mathrm{C} 18$ as well as from C20 fatty acids, and several studies indicate regulatory roles for at least some of these compounds in algal defense (reviewed by Potin et al., 2002; Pohnert, 2004).

Cellular perception of MAMPs has been shown to result in production of oxylipins and in biological effects. For example, concentrations of octadecanoid and eicosanoid oxylipins increased in Chondrus crispus after exposure to cell-free extracts of Acrochaete operculata (Bouarab et al., 2004). Two lipoxygenase isoforms were upregulated within $1 \mathrm{~d}$ after elicitor application. Moreover, inhibition of lipoxygenase abolished the natural resistance of $C$. crispus gametophytes toward $A$. operculata, which demonstrated that this resistance requires oxylipin signaling. Further, treat- ments of $C$. crispus sporophytes-usually susceptible to $A$. operculata - with C20 or C18 oxylipins induced a transient resistance. The study by Bouarab et al. (2004) thus confirmed the involvement of both $\mathrm{C} 18$ and $\mathrm{C} 20$ oxylipins in defense signalling in $C$. crispus.

MAMP-activated production of oxylipins was also observed in L.. digitata (Küpper et al., 2006). Within $30 \mathrm{~min}$ after treatment of $L$. digitata with two different LPS or with oligoguluronate, this brown alga released increased amounts of $\mathrm{C} 18$ and $\mathrm{C} 20$ free fatty acids. However, a concomitant accumulation of oxidized derivatives of linolenic and eicosapentaenoic acid was observed only after application of LPS, suggesting that oligoguluronate perception does not result in oxylipin production. Similarly, agar oligosaccharides did not activate oxylipin production in $G$. chilensis (U. Lion, Essen University, pers. comm.).

Further derivatization of $\mathrm{C} 18$ and $\mathrm{C} 20$ oxylipins leads to synthesis of jasmonic acid in vascular plants and of prostaglandins in metazoans. These cyclopentenones often act as defense hormones, in particular jasmonic acid (Farmer et al., 2003; Soberman and Christmas, 2003; Schaller et al., 2005; Stanley, 2006). Evidence exists that jasmonic acid, or structurally similar compounds (Pohnert, 2004), also play a role as secondary defense signals in macroalgae. For example, methyl jasmonate induced an increased biosynthesis of phlorotannins-often considered to be defense compounds - in the bladder wrack Fucus vesiculosus (Arnold et al., 2001) and transient resistance to A. operculata in $C$. crispus (Bouarab et al., 2004). Treatment of $C$. crispus with methyl jasmonate also resulted in a general increase in stress gene transcription, while the expression of genes involved in energy conversion and general metabolism was downregulated (Collén et al., 2006), which confirmed the hormone-like function of jasmonic acid (or structurally similar compounds) in this macroalga.

\section{Hypersensitive Response}

At the site of attempted attack by an avirulent pathogen, vascular plants typically respond with hypersensitive cell death (Heath, 2000), and similar responses have been reported from macroalgae. During the hypersensitive response (HR), vascular plants sacrifice infected and adjacent cells to limit pathogen spreading. The HR is a result of programmed cell death (apoptosis) and different from the accidental cell death that may be caused by extrinsic factors such as accumulation of phytotoxic compounds after a traumatic stress (Van Breusegem and Dat, 2006). The regulation of the HR involves sensing of changes in intracellular homeostasis of ROS such as $\mathrm{O}_{2}^{-} \bullet$ or $\mathrm{NO} \bullet$ during the oxidative burst (Delledonne et al., 2001), but due to the inherent toxic nature of these oxidants, their signaling function in the HR has long been masked.

Cell death is often observed during microbial infections 
of macroalgae. For example, alginate-degrading bacteria have been shown to induce cell death in Laminaria japonica (Liu et al., 2002a), but not in certain resistant clones that expressed a particularly high antioxidative capacity (Tang et al., 2002), suggesting that ROS accumulation after oligoguluronate perception was crucial for this symptom. Cell death was also observed in gracilarioids after infection with bacteria (Weinberger et al., 1994, 1997; Jaffray and Coyne, 1996; Schroeder et al., 2003). Application of agar oligosaccharide into the medium of Gracilaria sp. caused this symptom in apical cells, and simultaneous application of catalase reduced the effect, which indicated an involvement of ROS into cell death (Weinberger, 1999).

Uncoupling of respiration and phosphorylation is a prerequisite for programmed cell death (Fleury et al., 2002; Tiwari et al., 2002; Van Breusegem and Dat, 2006), leading to amplified ROS production and changes in ROS homeostasis, and such uncoupling was observed after exposure of Gracilaria sp. to agar oligosaccharides (Weinberger, 1999). The resulting respiratory increase was sensitive toward respiration inhibitors, such as rotenone and antimycin A, and application of these agents also reduced agar oligosaccharide-induced cell death in Gracilaria sp. significantly. In addition to mitochondria, chloroplasts were also involved in the regulation of agar oligosaccharide-activated cell death in Gracilaria sp. The effect was dependent on small doses of light (Weinberger et al., 1999), reminescent of findings with vascular plants which indicate an involvement of phytochrome light receptors in the regulation of the HR (Genoud et al., 2002).

Key enzymes activated during apoptosis that catalyze programmed cell death in vascular plants and in metazoans are nucleases and caspases, a family of highly specific proteases (Heath, 2000; Lam and del Pozo, 2004). Investigations with $L$. japonica revealed that cell death after infection with alginate-degrading microorganisms was dependent upon caspases, and DNA cleavage was also observed (Wang et al., 2004a). Alginate degrader-induced cell death in L. japonica therefore appears as a result of apoptosis, similar to the HR in vascular plants. Interestingly, overexpression of hypersensitive lesions in response to alginatedegrading bacteria may lead to massive losses of $L$. japonica sporelings in commercial kelp aquaculture and has been described as the so-called "rot disease" (Ding, 1992).

\section{The Defensive Value of Receptor-Mediated Immunity}

Irrespective of all similarities or differences with other host-pathogen systems, any defenses should, of course, result in a containment of pathogens. Indeed, exposure to MAMPs or PIMPs increases macroalgal resistance. In Gracilaria sp., treatment with agar oligosaccharides eliminated up to $55 \%$ of all associated bacteria within $1 \mathrm{~h}$ (Weinberger and Friedlander, 2000). Agarolytic bacterial strains that had been isolated from the surface of Gracilaria sp. proved to be particularly sensitive. Treatment with agar oligosaccharides also increased the resistance of Gracilaria chilensis against the epiphytic microalga Acrochaetium sp. (Weinberger, unpubl. data). After exposure to oligoguluronate, Laminaria digitata sporophytes became more resistant to infection with a brown algal endophyte, Laminariocolax tomentosoides (Küpper et al., 2002). The resistance increased progressively, reached its maximum $7 \mathrm{~d}$ after exposure, and persisted for more than one week. Similarly, Chondrus crispus gained in resistance against the endophyte Acrochaete operculata when it was treated with cell-free extract from A. operculata (Bouarab et al., 2004).

Innate immunity requires more than the general ability of an organism to perceive MAMPs or PIMPs and to activate a potentially defensive response after signal recognition: it also requires that the necessary concentrations of signals and defense compounds be reached under natural conditions. Host-pathogen interactions of vascular plants and animals typically take place in the phylloplane or lymph system, where concentrations of infochemicals and defense compounds can be more-or-less controlled by the host. In contrast, elicitors and defense compounds in macroalgapathogen interactions may be subject to constant dilution in the aquatic environment. It is therefore an obvious question whether they can ever reach efficient concentrations.

Analytical tools that allow the real-time quantification of MAMPs or PIMPs directly at the site of their release do not yet exist, but several studies indicate that molecular signals are generated during pathogen infections in sufficient amounts to trigger responses. In Laminaria japonica, early stages of infections with alginate-degrading bacteria have been shown to be characterized by responses similar to those of oligoguluronane exposure; for example, by an oxidative burst (Huang et al., 2002; Liu et al., 2002b) and by $\mathrm{Ca}^{2+}$ translocation events (Wang et al., 2004b), which indicates that oligoguluronates are apparently perceived. In pond aquaculture of Gracilaria sp., microbial decay of algal biomass resulted within $24 \mathrm{~h}$ in an accumulation of agar oligosaccharides that was potentially high enough to elicit an oxidative burst in all specimens of Gracilaria sp. that were present (Weinberger and Friedlander, 2000). A similar "neighbor effect" might also be possible in other closed water bodies, such as rock pools.

The quantification of unstable compounds such as ROS, in real time and at the site of their potential defensive action, poses a challenge similar to the quantification of MAMPs or PIMPs. Indications of direct defensive effects of algal responses after pathogen perception have nontheless been reported. Küpper et al. (2002) inhibited the capacity for an oxidative burst in Laminaria digitata and Macrocystis pyrifera by adding diphenylene iodonium to the medium, which rendered these kelps unable to defend themselves against decomposition by the same bacterial flora that under normal 
conditions caused no damage to them. Seaweed-associated agarolytic bacteria (Weinberger and Friedlander, 2000) and alginate-hydrolyzing bacteria (Küpper et al., 2001) were generally sensitive toward the concentrations of $\mathrm{H}_{2} \mathrm{O}_{2}$ that were observed in the algal medium after exposure to the elicitor, suggesting that direct cytotoxicity of ROS may lead to an elimination of these microorganisms.

In addition, many macroalgae have cell-wall-located haloperoxidases, which are limited in their activity by $\mathrm{H}_{2} \mathrm{O}_{2}$ and which generate hypohalous acids and various halocarbons, such as bromoform $\left(\mathrm{CHBr}_{3}\right)$ (Carpenter and Liss, 2000). It has long been disputed whether these compounds play a role in algal defense or are just byproducts of ROS detoxification (Manley, 2002). However, hypohalous acids generated by $L$. digitata have been shown to interfere with $N$-acyl-homoserine lactone-mediated quorum sensing, which regulates the formation of bacterial biofilms (Borchardt et al., 2001). Moreover, a study by Paul et al. (2006) demonstrated that bacteria associated with the red alga Asparagopsis armata increased 14- to 20-fold when no $\mathrm{CHBr}_{3}$ could be synthesized by their host due to bromide $\left(\mathrm{Br}^{-}\right)$depletion. Bacteria that had been isolated from $A$. armata in $\mathrm{Br}^{-}$-depleted conditions proved to be more sensitive toward $\mathrm{CHBr}_{3}$ than were bacteria that had been isolated when $\mathrm{Br}^{-}$was present, which strongly suggests that the increase in bacterial numbers resulted from lack of $\mathrm{CHBr}_{3}$ rather than from other effects of $\mathrm{Br}^{-}$-depletion.

Algal $\mathrm{CHBr}_{3}$ production may therefore have a defensive value, provided that the rate of release is sufficiently high. The rate of $\mathrm{CHBr}_{3}$ release by A. armata (Marshall et al., 1999; Paul et al., 2006) is in the same order of magnitude as in $L$. digitata that have not been exposed to an elicitor (Carpenter and Liss, 2000) or Gracilaria sp. (151 ng $\mathrm{gDW}^{-1} \mathrm{~h}^{-1}$ [where DW is dry weight of algal tissue], F. Weinberger, B. Coquimpot, S. Forner, P. Morin, B. Kloareg, P. Potin, unpubl. data). Exposure of $L$. digitata to oligoguluronate immediately accelerated $\mathrm{CHBr}_{3}$ production by about $250 \%$ (Palmer et al., 2005), and an increase by $780 \%$ was observed with Gracilaria sp. after treatment with agar oligosaccharide (Weinberger, Coquimpot et al., unpubl. data). All together, these findings suggest that halogenated compounds and ROS can be generated by kelps and gracilarioids in sufficiently high amounts to kill or repel microorganisms and that their production is accelerated during the oxidative burst. Compared to the small number of studies that were conducted with macroalgae, relatively many indications of direct toxic effects of oxidative burst products upon associated microorganisms exist. This contrasts with the relatively few examples that have been described for vascular plants, suggesting that more ROS are excreted by algae, possibly to compensate for dilution effects.

\section{The Evolution of Innate Immunity}

Major principles of innate immunity appear strikingly similar among distant eukaryotic clades, which seemingly indicates that they are evolutionary ancient. However, comparisons of the molecular structures of innate receptors of animals and vascular plants reveal important differences (Nürnberger et al., 2004; Ausubel, 2005), suggesting that similarities are the result of coevolutionary processes. The constitutive presence of innate receptors not only allows for particularly fast responses to pathogen attacks, but also is the necessary basis for a reliable cellular distinction between self and non-self (Nürnberger and Lipka, 2005), and this could be the reason that these receptors evolved several times independently.

Other components of innate immunity are apparently conserved. For example, the main subunits of NADPH oxidase in mammalian phagocytes, vascular plants, diatoms, and the red macroalgae Porphyra yezoensis and Chondrus crispus are structurally related (Keller et al., 1998; Torres and Dangl, 2005; Hervé et al., 2006), which confirms that this protein is evolutionary ancient. Eicosanoid and prostaglandin signaling may also be a common heritage of most or even all eukaryotes, which got lost only in spermatophytes (Bouarab et al., 2004). Jasmonate signaling probably evolved after the primary chloroplast endosymbiosis but before any secondary endosymbiotic events (Fig. 2) and is therefore potentially a common trait of all photosynthetically active eukaryotes (Bouarab et al., 2004). The same seems to be true for at least some components of apoptosis, which involves caspases in brown algae, vascular plants, and metazoans.

The fact that NADPH oxidase, oxylipin signaling pathways, and apoptosis appear to be evolutionary ancient is nonetheless no strong indication of a common origin of innate immunity. All three are not specific components of immunity regulation, but rather are generally employed in cellular stress management, and their similar functions in different eukaryotes could for this reason be a result of coevolution.

Interestingly, vascular plants and macroalgae share some immunological traits that are missing in metazoans-for example, the capacity to perceive PIMPs. Only the isolation and characterization of macroalgal MAMP and PIMP receptors in the future will allow for a final decision about whether innate immunity evolved only once or several times independently in photosynthetic eukaryotes.

\section{Conclusion and Outlook: Challenges for Ecologists!}

Considerable evidence of innate immunity in kelps, gracilarioids, and Chondrus crispus has accumulated during the last years (Table 1). Obvious similarities exist between the responses of kelps to alginate-degrading microorganisms and of vascular plants to pectin degraders. The re- 
sponse of Gracilaria sp. to agar degraders also fits into this pattern, but differs in some aspects from that of the closely related Gracilaria chilensis. Nontheless, both responses affected pathogens in bioassays. This still needs to be demonstrated for macroalgal responses to LPS, which again appear similar to those of other eukaryotes. The response of C. crispus to cell-free extracts of Acrochaete operculata also shows important similarities with the innate immunity of other eukaryotes, while nature and origin of the active signal still remain enigmatic.

Yet relatively few examples of macroalgal innate immunity are known. This might mean that they are rare. However, the identification of molecular defense elicitors is time-consuming, and the lack of evidence of innate immunity in entire macroalgal clades such as chlorophytes and charophytes could simply reflect a lack of investigations.

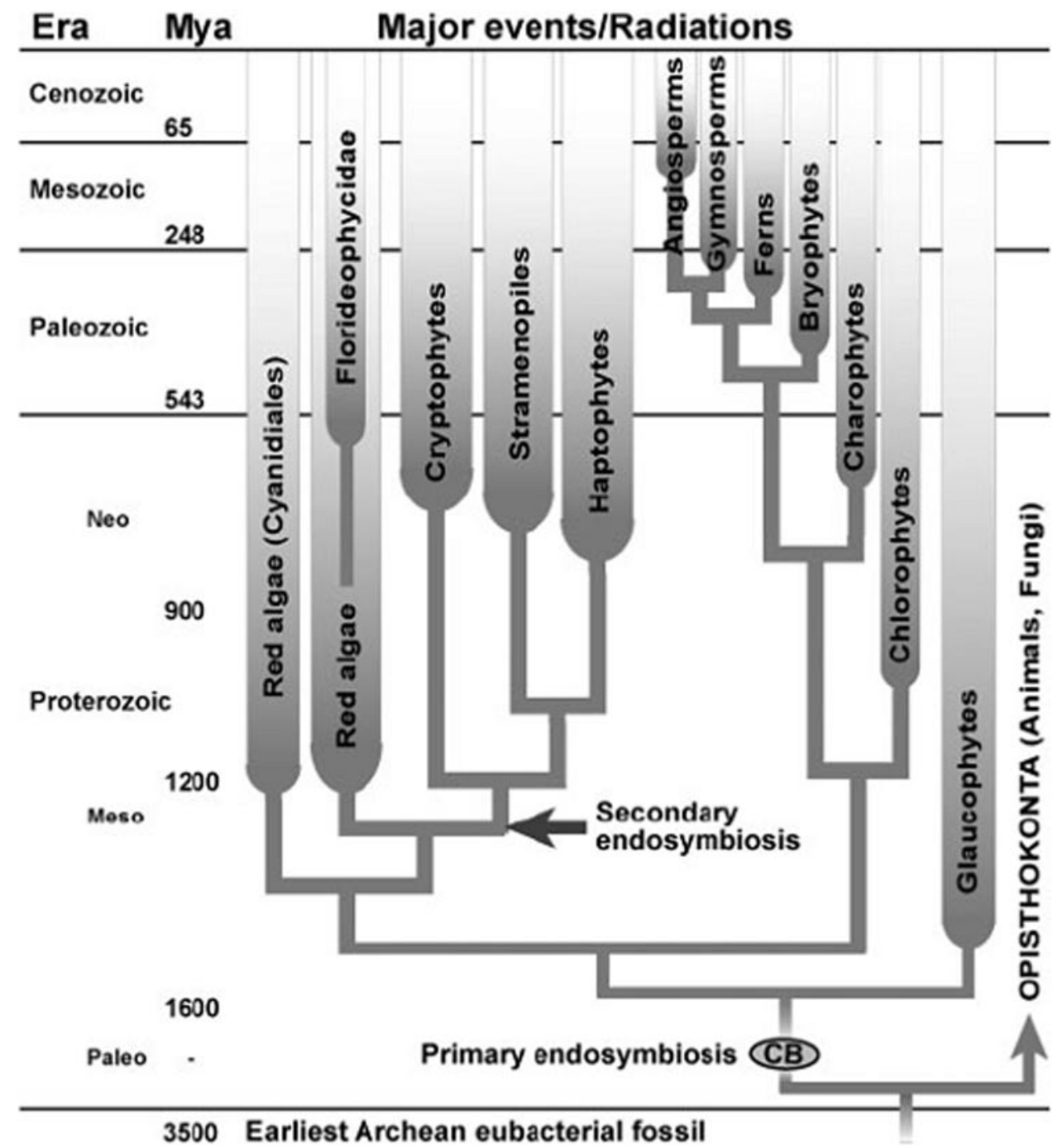

Figure 2. A schematic representation of the evolutionary relationships and divergence times for plastidbearing eukaryotes (reproduced from Yoon, H. S., J. D. Hackett, C. Ciniglia, G. Pinto, and D. Bhattacharya. 2003. A molecular timeline for the origin of photosynthetic eukaryotes. Mol. Biol. Evol. 21:809-818, by permission of the Society for Molecular Biology and Evolution and Oxford University Press). This tree was generated using maximum likelihood molecular clock methods, based upon a plastid-gene phylogeny with Bayesian inference. Nodes in the tree were constrained with six reliable fossil dates and a maximum age of 3500 millions of years based on the earliest known eubacterial fossil. The photosynthetic groups are outgroup-rooted with the Opisthokonta, which putatively ancestrally lacked a plastid. The branches on which the cyanobacterial (CB) primary and red algal secondary endosymbioses occurred are shown. Only red macroalgae (including Florideophycidae) and green macroalgae (including chlorophytes and charophytes) belong to the plant kingdom (Moreira et al., 2000; Baldauf, 2003; Palmer, 2003). Brown macroalgae belong to the stramenopiles—and thus to the same phylum as diatoms - and have arisen from a secondary endosymbiosis between an ancestral unicellular red alga and a second colorless protist. 
The first herbivore-associated molecular pattern that induces increased resistance to grazing in a macroalga has recently been identified (Coleman et al., 2007): the protein $\alpha$-amylase from mollusc saliva was apparently perceived by the brown alga Ascophyllum nodosum, which responded with increased synthesis of phlorotannin and reduced pallatability to the snail Littorina obtusata. This is reminescent of the recognition of specific components in the oral secretions of lepidopteran larvae by vascular plants (for a review, see Kessler and Baldwin, 2002).

So far, such examples of specific cellular recognition of grazers are an exception rather than a rule. Antigrazing defense in animals usually relies upon neuroreceptors, while vascular plants respond nonspecifically to wounding-irrespective of its cause. Wounding results in cell disintegration, in contact of phospholipases and lipids, subsequently in release of unsaturated fatty acids, and eventually in the formation of oxylipins (Kessler and Baldwin, 2002). Similar effects of wounding are also known from macroalgae (Schnitzler et al., 2001; Lion et al., 2006), and induction of macroalgal antiherbivore defenses by wounding has been reported (Toth and Pavia, 2007). However, more evidence of induced macroalgal antiherbivore defenses requiring chemical cues has been reported (Amsler, 2001; Toth and Pavia, 2007). These cues obviously must be perceived, and further examples of receptor-mediated defense against herbivores will possibly be detected in macroalgae. Additional examples will not only increase our understanding of seaweed-grazer interactions, but also allow us to widen the general concept of innate immunity. So far, innate immunity has been regarded only as the molecular basis of antimicrobial defenses (Nürnberger et al., 2004; Ausubel, 2005), and the few known examples of cellular perception of grazers were seen as exceptional. However, information on nonmodel organisms such as macroalgae is still largely missing, and long-standing "exceptions" may turn out to be "rules" in the future. A striking example for such a devolopment is the recent finding of $\mathrm{C} 20$ oxylipins as relatively widely distributed signaling compounds that are missing only in spermatophytes.

Molecular biologists are now challenged to isolate and characterize the receptors that are the basis of macroalgal innate immunity. This will not only be the final proof that these receptors exist, but it will also allow for a clear-cut decision on their evolutionary origin. Another important task for the coming years - in addition to further elucidating the signaling pathways involved-will be to analyze patterns of gene expression after defenses were elicited. The few known examples in macroalgae of gene induction after perception of a defense signal were often detected on the basis of an informed guess. Systematic comparisons of gene transcripts in macroalgae that have and have not been exposed to an elicitor should give much more comprehensive indications of whether and which defense mechanisms are induced after signal perception.

The molecular concept of macroalgal innate immunity has provided important new insights into seaweed-microbe interactions, and it now needs to be complemented and further strengthened with a convincing ecological perspective on pathogen-induced defense. So far, the existence of macroalgal innate immunity against microorganisms has been demonstrated mainly in laboratory studies, using simplified host-pathogen systems and standardized environmental conditions. Ecologists are now challenged to evaluate the relevance and functionality of these mechanisms under natural conditions, where genetically more diverse macroalgae are subject to varying conditions and are associated with complex interacting populations of micro- and macroorganisms. Induced antimicrobial defense may potentially affect macrofoulers (since their settlement often depends upon bacterial biofilms; see also Steinberg and DeNys, 2002) or the algal palatability to grazers.

Early stages of innate immune responses are typically characterized by transient signal and defense compound accumulation in and above the algal cell wall. The signals involved are usually complex and active at low concentrations in the nanomolar range, while the defense compounds involved are often short-lived (such as, for example, ROS). The demonstration that, under natural conditions, sufficiently high concentrations of these compounds are reached to cause an attributed effect is highly demanding, but necessary for the final proof of ecological relevance. In many cases this demonstration will probably require the development of new analytical tools that allow the quantification of signals and defense compounds in vivo, in situ, or both (La Barre et al., 2004).

\section{Literature Cited}

Agrawal, A. A., and R. Karban. 1999. Why induced defenses may be favored over constitutive strategies in plants. Pp. 45-61 in The Ecology and Evolution of Inducible Defenses, R. Tollrian and C. D. Harvell, eds. Princeton University Press, Princeton, NJ.

Amatore, C., S. Arbault, C. Bouton, K. Coffi, J.-C. Drapier, H. Ghandour, and Y. Tong. 2006. Monitoring in real time with a microelectrode the release of reactive oxygen and nitrogen species by a single macrophage stimulated by its membrane mechanical depolarization. Chembiochem 7: 653-661.

Amsler, C. D. 2001. Induced defenses in macroalgae: The herbivore makes a difference. J. Phycol. 37: 353-356.

Amsler, C. D., and V. A. Fairhead. 2006. Defensive and sensory chemical ecology of brown algae. Adv. Bot. Res. 43: 1-91.

Armstrong, E., L. M. Yan, K. G. Boyd, P. C. Wright, and J. G. Burgess. 2001. The symbiotic role of marine microbes on living surfaces. Hydrobiologia 461: 37-40.

Arnold, T. M., N. M. Targett, C. E. Tanner, W. I. Hatch, and K. E. Ferrari. 2001. Evidence for methyl-jasmonate induced phlorotannin production in Fucus vesiculosus (Phaeophyceae). J. Phycol. 37: 10261029.

Ashen, J. B., and L. J. Goff. 2000. Molecular and ecological evidence 
for species specificity and coevolution in a group of marine algalbacterial symbioses. Appl. Environ. Microbiol. 66: 3024-3030.

Ausubel, F. M. 2005. Are innate immune signalling pathways in plants and animals conserved? Nat. Immun. 6: 973-979.

Baldauf, S. L. 2003. The deep roots of eukaryotes. Science 300: 17031706.

Banfi, B., F. Tirone, I. Durussel, J. Krisz, P. Moskowa, G. Z. Molnar, K.-H. Krause, and J. A. Cox. 2005. Mechanism of $\mathrm{Ca}^{2+}$ activation of the NADPH oxidase 5 (NOX5). J. Biol. Chem. 279: 18583-18591.

Blee, E. 2002. Impact of phyto-oxylipins in plant defense. Trends Plant Sci. 7: 315-322.

Borchardt, S. A., E. J. Allain, J. J. Michels, G. W. Stearns, R. F. Kelly, and W. F. McCoy. 2001. Reaction of acylated homoserine lactone bacterial signaling molecules with oxidized halogen antimicrobials. Appl. Environ. Microbiol. 67: 3174-3179.

Bouarab, K., P. Potin, J. Correa, and B. Kloareg. 1999. Sulfated oligosaccharides mediate the interaction between a marine red alga and its green algal pathogenic endophyte. Plant Cell 11: 1635-1650.

Bouarab, K., F. Adas, E. Gaquerel, B. Kloareg, J.-P. Salaün, and P. Potin. 2004. The innate immunity of a marine red alga involves oxylipins from both the eicosanoid and octadecanoid pathways. Plant Physiol. 135: 1838-1848.

Boyd, L. A. 2006. Can the durability of resistance be predicted? J. Sci. Food Agric. 86: 2523-2526.

Carpenter, E. J., and P. S. Liss. 2000. On temperate sources of bromoform and other reactive organic bromine gases. J. Geophys. Res. 105D: 20539-20547.

Coleman, R. A., S. J. Ramchunder, A. J. Moody, and A. Foggo. 2007. An enzyme in snail saliva induces herbivore-resistance in a marine alga. Funct. Ecol. 21: 101-106.

Collén, J., C. Hervé, I. Guisle-Marsollier, J. J. Léger, and C. Boyen. 2006. Expression profiling of Chondrus crispus (Rhodophyta) after exposure to methyl jasmonate. J. Exp. Bot. 57: 3869-3881.

Correa, J. A. 1996. Infectious diseases of marine algae: current knowledge and approaches. Pp. 149-180 in Progress in Phycological Research, F. E. Round and D. J. Chapman, eds. Biopress, Bristol, United Kingdom.

Delledonne, M., J. Zeier, A. Marocco, and C. Lamb. 2001. Signal interactions between nitric oxide and reactive oxygen intermediates in the plant hypersensitive disease resistance response. Proc. Natl. Acad. Sci. USA 98: $13454-13459$.

Ding, M. 1992. The effects of the environmental factors on Laminaria disease caused by alginic acid decomposing bacteria. Acta Oceanol. Sinica 11: 123-130.

Dobretsov, S. V., and P.-Y. Qian. 2002. Effect of bacteria associated with the green alga Ulva reticulata on marine micro- and macrofouling. Biofouling 18: 217-228.

Engel, S., P. R. Jensen, and W. Fenical. 2002. Chemical ecology of marine microbial defense. J. Chem. Ecol. 28: 1971-1985.

Erbs, G., and M. A. Newman. 2003. The role of lipopolysaccharides in the induction of plant defence responses. Mol. Plant Pathol. 4: 421425.

Farmer, E. E., E. Alméras, and V. Krishnamurthy. 2003. Jasmonates and related oxylipins in plant responses to pathogenesis and herbivory. Curr. Opin. Plant Biol. 6: 372-378.

Farnell, M. B., T. L. Crippen, H. He, C. L. Swaggerty, and M. H. Kogut. 2003. Oxidative burst mediated by toll like receptors (TLR) and CD14 on avian heterophils stimulated with bacterial toll agonists. Dev. Comp. Immunol. 27: 423-429.

Felix, G., M. Regennass, and T. Boller. 1993. Specific perception of subnanomolar concentrations of chitin fragments by tomato cells: induction of extracellular alkalinization, changes in protein phosphorylation, and establishment of a refractory state. Plant J. 4: 307-316.
Feusner, I., and C. Wasternack. 2002. The lipoxygenase pathway. Annu. Rev. Plant Biol. 53: 275-297.

Fleury, C., B. Mignotte, and J.-L. Vayssière. 2002. Mitochondrial reactive oxygen species in cell death signaling. Biochimie 84: 131-141.

Genoud, T., A. J. Buchala, N.-H. Chua, and J.-P. Métraux. 2002. Phytochrome signalling modulates the SA-perceptive pathway in Arabidopsis. Plant J. 31: 87-95.

Grant, J. J., and G. J. Loake. 2000. Role of reactive oxygen intermediates and cognateredox signaling in disease resistance. Plant Physiol. 124: 21-29.

He, H., M. B. Farnell, and M. H. Kogut. 2003. Inflammatory agonist stimulation and signal pathway of oxidative burst in neonatal chicken heterophils. Comp. Biochem. Physiol. A 135: 177-184.

Heath, M. C. 2000. Hypersensitive response-related death. Plant Mol. Biol. 44: 321-334.

Hervé, C., T. Tonon, J. Collén, E. Corre, and C. Boyen. 2006. NADPH oxidases in Eukaryotes: red algae provide new hints! Curr. Genet. 49: 190-204.

Huang, J., X. Tang, T. Liu, and Y. Li. 2002. Alteration of activated oxygen and antioxidant system in kelp during alginic acid decomposing bacteria infection. J. Ocean Univ. Qingdao 32: 574-578 (in Chinese with English summary).

Jabs, T., M. Tschöpe, C. Colling, K. Hahlbrock, and D. Scheel. 1997. Elicitor-stimulated ion fluxes and $\mathrm{O}_{2}^{-}$from the oxidative burst are essential components in triggering defense gene activation and phytoalexin synthesis in parsley. Proc. Natl. Acad. Sci. USA 94: 4800-4805.

Jaffray, A. E., and V. E. Coyne. 1996. Development of an in situ assay to detect bacterial pathogens of the red alga Gracilaria gracilis (Stackhouse) Steentoft, Irvine et Farnham. J. Appl. Phycol. 8: 409-414.

Jaffray, A. E., R. J. Anderson, and V. E. Coyne. 1997. Investigation of bacterial epiphytes of the agar-producing red seaweed Gracilaria gracilis (Stackhouse) Steentoft, Irvine et Farnham from Saldanha Bay, South Africa and Luderitz, Namibia. Bot. Mar. 40: 569-576.

Järemo, J., J. Tuomi, and P. Nilsson. 1999. Adaptive status of systemic and localized defense responses in plants. Pp. 33-44 in The Ecology and Evolution of Inducible Defenses, R. Tollrian and C. D. Harvell, eds. Princeton University Press, Princeton, NJ.

Keller, T., H. G. Demude, D. Werner, P. Doerner, R. A. Dixon, and C. Lamb. 1998. A plant homolog of the neutrophil NADPH oxidase gp91 ${ }^{\text {phox }}$ subunit gene encodes a plasma membrane protein with $\mathrm{Ca}^{2+}$ binding motifs. Plant Cell 10: 255-266.

Kessler, A., and I. T. Baldwin. 2002. Plant responses to insect herbivory: the emerging molecular analysis. Аnпи. Rev. Plant Biol. 53: 299-328.

Küpper, F. C., B. Kloareg, J. Guern, and P. Potin. 2001. Oligoguluronates elicit an oxidative burst in the brown algal kelp Laminaria digitata. Plant Physiol. 125: 278-291.

Küpper, F. C., D. G. Müller, A. F. Peters, B. Kloareg, and P. Potin. 2002. Oligoalginate recognition and oxidative burst play a key role in natural and induced resistance of sporophytes of Laminariales. J. Chem. Ecol. 28: 2057-2080.

Küpper, F. C., E. Gaquerel, E.-M. Boneberg, S. Morath, J.-P. Salaün, and P. Potin. 2006. Early events in the perception of lipopolysaccharides in the brown alga Laminaria digitata include an oxidative burst and activation of fatty acid oxidation cascades. J. Exp. Bot. 57: 1991-1999.

La Barre, S., F. Weinberger, N. Kervarec, and P. Potin. 2004. Monitoring defensive responses in macroalgae-limitations and perspectives. Phytochem. Rev. 3: 371-379.

Lam, E., and O. del Pozo. 2004. Caspase-like protease involvement in the control of plant cell death. Plant Mol. Biol. 44: 417-428.

Largo, D. B., K. Fukami, and T. Nishijima. 1995. Occasional pathogenic bacteria promoting ice-ice disease in the carrageenan-producing 
red algae Kappaphycus alvarezii and Eucheuma denticulatum (Solieriaceae, Gigartinales, Rhodophyta). J. Appl. Phycol. 7: 545-554.

Lee, H. Y., S. C. Bahn, J. S. Shin, I. Hwang, K. W. Back, J. H. Doelling, and B. T. S. Ryu. 2005. Multiple forms of secretory phospholipase A2 in plants. Prog. Lipid. Res. 44: 52-67.

Lin, W., W. Zhang, X. Yan, and D. Duan. 2004. Distribution and reinfection of alginic acid decomposing bacteria on juvenile Laminaria japonica. Oceanol. Limnol. Sinica 35: 562-567.

Lion, U., T. Wiesemeier, F. Weinberger, J. Beltrán, V. Flores, S. Faugeron, J. Correa, and G. Pohnert. 2006. Phospholipases and galactolipases trigger oxylipin-mediated wound-activated defence in the red alga Gracilaria chilensis against epiphytes. Chembiochem 7: $457-462$.

Liu, C., L. Wang, M. Wang, and X. Tang. 2002a. Difference analysis of infection activity of alginic acid decomposing bacteria infecting Laminaria japonica. Mar. Sci. Haiyang Kexue 26: 44-47 (in Chinese with English abstract).

Liu, C., Z. Yang, and X. Tang. 2002b. Generality of production of reactive oxygen species under infection of alginic acid decomposing bacteria in Laminaria japonica. Mar. Fish. Res. Haiyang Shuichan Yanjiu 23: 33-36 (in Chinese with English abstract).

Mackey, D., and A. J. McFall. 2006. MAMPs and MIMPs: proposed classifications for inducers of innate immunity. Mol. Microbiol. 61: 1365-1371.

Manley, S. L. 2002. Phytogenesis of halomethanes: a product of selection or a metabolic accident? Biogeochemistry 60: 163-180.

Marshall, R. A., D. B. Harper, C. W. McRoberts, and M. J. Dring. 1999. Volatile bromocarbons produced by Falkenbergia stages of Asparagopsis spp. (Rhodophyta). Limnol. Oceanogr. 44: 1348-1352.

Mathieu, Y., A. Kurdijan, H. Xia, J. Guern, A. Koller, M. D. Spiro, M. A. O'Neill, P. Albersheim, and A. Darvill. 1991. Membrane responses induced by oligogalacturonides in suspension-cultured tobacco cells. Plant J. 1: 333-343.

Matsuo, Y., H. Imagawa, M. Nishizawa, and Y. Shizuri. 2005. Isolation of an algal morphogenesis inducer from a marine bacterium. Science 307: 1598.

Meier, B. 1996. Regulation of the superoxide releasing system in human fibroblasts. Adv. Exp. Med. Biol. 387: 113-116.

Meusnier, I., J. L. Olsen, W. T. Stam, C. Destombe, and M. Valero. 2001. Phylogenetic analyses of Caulerpa taxifolia (Chlorophyta) and of its associated bacterial microflora provide clues to the origin of the Mediterranean introduction. Mol. Ecol. 10: 931-946.

Meyer, A., A. Pühler, and K. Niehaus. 2001. The lipopolysaccharides of the phytopathogen Xanthomonas campestris pv. campestris induce an oxidative burst reaction in cell cultures of Nicotiana tabacum. Planta 213: 214-222.

Moreira, D., H. LeGuyader, and H. Philippe. 2000. The origin of red algae and the evolution of chloroplasts. Nature 405: 69-72.

Navazio, L., R. Moscatiello, D. Bellincampi, B. Baldan, F. Meggio, M. Brini, C. Bowler, and P. Mariani. 2002. The role of calcium in oligogalacturonide-activated signalling in soybean cells. Planta 215: $596-605$.

Nürnberger, T., and V. Lipka. 2005. Non-host resistance in plants: new insights into an old phenomenon. Mol. Plant Pathol. 6: 335-345.

Nürnberger, T., F. Brunner, B. Kemmerling, and L. Piater. 2004. Innate immunity in plants and animals: striking similarities and obvious differences. Immunol. Rev. 198: 249-266.

Palmer, C. J., T. L. Anders, L. J. Carpenter, F. C. Küpper, and G. B. McFiggans. 2005. Iodine and halocarbon response of Laminaria digitata to oxidative stress and links to atmospheric new particle production. Environ. Chem. 2: 282-290.

Palmer, J. P. 2003. The symbiotic birth and spread of plastids: how many times and whodunit? J. Phycol. 39: 4-11.

Paul, N. A., R. de Nys, and P. D. Steinberg. 2006. Chemical defence against bacteria in the red alga Asparagopsis armata: linking structure with function. Mar. Ecol. Prog. Ser. 306: 87-101.

Pitzschke, A., C. Forzani, and H. Hirt. 2006. Reactive oxygen species signalling in plants. Antioxid. Redox Signaling 8: 1757-1764.

Pohnert, G. 2004. Chemical defense strategies of marine organisms. Top. Curr. Chem. 239: 179-219.

Potin, P., K. Bouarab, J.-P. Salaün, G. Pohnert, and B. Kloareg. 2002. Biotic interactions of marine algae. Curr. Opin. Plant Biol. 5: 308 317.

Remer, K. A., M. Brcic, and T. W. Jungi. 2003. Toll-like receptor-4 is involved in eliciting an LPS-induced oxidative burst in neutrophils. Immunol. Lett. 85: 75-80.

Sagi, M., and R. Fluhr. 2001. Superoxide production by plant homologues of the gp91 $1^{\text {phox }}$ NADPH oxidase. Modulation of activity by calcium and tobacco mosaic virus infection. Plant Physiol. 126: $1281-$ 1290 .

Schaller, F., A. Schaller, and A. Stintzi. 2005. Biosynthesis and metabolism of jasmonates. J. Plant Growth Regul. 23: 179-199.

Schnitzler, I., G. Pohnert, M. Hay, and W. Boland. 2001. Chemical defense of brown algae (Dictyopteris spp.) against the herbivorous amphipod Amphitoe longimana. Oecologia 126: 515-521.

Schroeder, D. C., M. A. Jaffer, and V. E. Coyne. 2003. Investigation of the role of a beta (1-4) agarase produced by Pseudoalteromonas gracilis B9 in eliciting disease symptoms in the red alga Gracilaria gracilis. Microbiology 149: 2919-2929.

Soberman, R. J., and P. Christmas. 2003. The organization and consequences of eicosanoid signaling. J. Clin. Investig. 111: 1107-1113.

Spiro, M. D., B. L. Ridley, S. Eberhard, K. A. Kates, Y. Mathieu, M. A. O’Neill, D. Mohnen, J. Guern, A. Darvill, and P. Albersheim. 1998. Biological activity of reducing-end-derivatized oligogalacturonides in tobacco tissue cultures. Plant Physiol. 116: $1289-1298$.

Stanley, D. 2006. Prostaglandins and other eicosanoids in insects. Annu. Rev. Entomol. 51: 25-44.

Steinberg, P. D., and R. deNys. 2002. Chemical mediation of colonization of seaweed surfaces. J. Phycol. 38: 621-629.

Tang, X., Y. Wang, K. Li, and Z. Yang. 2002. Relationship between resistance against alginic-acid-decomposing bacteria and antioxidative activity in Laminaria japonica. J. Fish. Sci. China 9: 14-17 (in Chinese with English abstract).

Tiwari, B. S., B. Belenghi, and A. Levine. 2002. Oxidative stress increased respiration and generation of reactive oxygen species, resulting in ATP depletion, opening of mitochondrial permeability transition, and programmed cell death. Plant Physiol. 128: 1271-1281.

Torres, M. A., and J. Dangl. 2005. Functions of the respiratory burst oxidase in biotic interactions, abiotic stress and development. Curr. Opin. Plant Biol. 8: 397-403.

Toth, G., and H. Pavia. 2007. Induced herbivore resistance in seaweeds: a meta-analysis. J. Ecol. 95: 425-434.

Van Breusegem, F., and J. F. Dat. 2006. Reactive oxygen species in plant death. Plant Physiol. 141: 384-390.

Wang, G.-G., W. Lin, L.-J. Zhang, X.-J. Yan, and D.-L. Duan. 2004a. Programmed cell death in Laminaria japonica (Phaeophyta) tissues infected with alginic acid decomposing bacterium. Prog. Nat. Sci. 14: $1064-1068$.

Wang, G.-G., X.-Y. Liu, X.-H. Li, W. Lin, X.-J. Yan, and D.-L. Duan. 2004b. Spatial-temporal changes of $\mathrm{Ca}^{2+}$ distribution in cells of Laminaria japonica infected by alginic acid degradation bacteria. Chin. J. Oceanol. Limnol. 9(supplement): 36.

Wang, L., X. Tang, M. Wang, P. Zhang, and C. Liu. 2004c. Studies on physiological and biochemical changes of Laminaria japonica during the occurrence of rot disease. II. Changes of PAL activity, PPO activity and polyphenol content. Adv. Mar. Sci. 22: 73-76 (in Chinese with English abstract).

Weinberger, F. 1999. Epiphyte-host interactions: Gracilaria conferta 
(Rhodophyta) and associated bacteria. Ph.D. dissertation, ChristianAlbrechts Universität, Kiel, Germany.

Weinberger, F., and M. Friedlander. 2000. Response of Gracilaria conferta (Rhodophyta) to oligoagars results in defense against agardegrading epiphytes. J. Phycol. 36: 1079-1086.

Weinberger, F., M. Friedlander, and W. Gunkel. 1994. A bacterial facultative parasite of Gracilaria conferta. Dis. Aquat. Org. 18: 135141.

Weinberger, F., H. G. Hoppe, and M. Friedlander. 1997. Bacterial induction and inhibition of a fast necrotic response in Gracilaria conferta (Rhodophyta). J. Appl. Phycol. 9: 277-285.

Weinberger, F., M. Friedlander, and H. G. Hoppe. 1999. Oligoagars elicit a physiological response in Gracilaria conferta (Rhodophyta). J. Phycol. 35: 747-755.

Weinberger, F., C. Richard, B. Kloareg, Y. Kashman, H. G. Hoppe, and M. Friedlander. 2001. Structure-activity relationships of oligoagar elicitors toward Gracilaria conferta (Rhodophyta). J. Phycol. 37: 418-426.

Weinberger, F., G. Pohnert, B. Kloareg, and P. Potin. 2002. A signal released by an enclophytic attacker acts as a substrate for a rapid defensive reaction of the red alga Chondrus crispus. Chembiochem 3: $1260-1263$.

Weinberger, F., P. Leonardi, A. Miravalles, J. A. Correa, U. Lion, B. Kloareg, and P. Potin. 2005a. Dissection of two distinct defenserelated responses to agar oligosaccharides in Gracilaria chilensis (Rhodophyta) and Gracilaria conferta (Rhodophyta). J. Phycol. 41: 863873.

Weinberger, F., G. Pohnert, M. L. Berndt, K. Bouarab, B. Kloareg, and P. Potin. 2005b. Apoplastic oxidation of L-asparagine is involved in the control of the green algal endophyte Acrochaete operculata Correa \& Nielsen by the red seaweed Chondrus crispus Stackhouse. J. Exp. Bot. 56: 1317-1326.

Zeidler, D., U. Zähringer, I. Gerber, I. Dubery, T. Hartung, W. Bors, P. Hutzler, and J. Durner. 2004. Innate immunity in Arabidopsis thaliana: lipopolysaccharides activate nitric oxide synthase (NOS) and induce defense genes. Proc. Nat. Acad. Sci. USA 101: 15811-15816.

Zheng, L., X. Han, H. Chen, W. Lin, and X. Yan. 2005. Marine bacteria associated with marine macroorganisms: the potential antimicrobial resource. Ann. Microbiol. 55: 119-124. 